\title{
Endogenous Market Structures and Innovation by Leaders: An Empirical Test
}

\author{
By Dirk Czarnitzki†, Federico Etroł and Kornelius Kraft†† \\ $\dagger K U$ Leuven, Belgium and ZEW Mannheim, Germany $\quad \ddagger$ Ca’ Foscari University of Venice and \\ Intertic, Italy $\quad \dagger T U$ Dortmund University and ZEW Mannheim, Germany
}

Final version received 27 November 2012.

\begin{abstract}
Models of competition for the market with endogenous market structures show that, contrary to the Arrow view, an endogenous entry threat induces the average firm to invest less in $R \& D$ and the incumbent leader to invest more. We test these predictions using a unique dataset for the German manufacturing sector (the Mannheim Innovation Panel). In line with our predictions, endogenous entry threats as perceived by the firms (in survey data) reduce R\&D intensity for an average firm, but they increase it for an incumbent leader. These results hold after a number of robustness tests with instrumental variable regressions.
\end{abstract}

\section{INTRODUCTION}

There is a lot of debate on the role of market leaders in investing in $R \& D$ and promoting technological progress. A commonly held view is that firms invest more in a more competitive market where the entry pressure is stronger, and incumbents tend to be less innovative than their followers, so that the persistence of their dominance is typically the signal of market power and of the lack of entry pressure. This view is often associated with Arrow (1962), who has shown that incumbents have lower incentives to invest in R\&D than outsiders, and that in case of free entry in competition for the market they do not invest at all, leaving innovative activity to the outsiders. We adopt a Schumpeterian perspective and challenge this view from both a theoretical and an empirical perspective, showing under which conditions incumbent leaders do invest more than other firms, and providing empirical evidence in support of our thesis.

There are few competing explanations for innovation by incumbents in Schumpeterian models. The simplest one, due to Segerstrom (2007), relies on the fact that incumbents may have a technological advantage in the R\&D activity. This assumption may be realistic in certain sectors and allows one to study monopoly persistence, but it is basically equivalent to assuming the solution of the Arrow paradox rather than solving it. ${ }^{1}$ Acemoglu (2009, ch. 14) and Acemoglu and Cao (2010) have proposed a different rationale for innovation by incumbents. This may be due to the fact that only incumbents can invest in incremental innovations (because outsiders would infringe their patents through small improvements), while entrants invest in more radical innovations. In such a way, both incumbents and outsiders invest, and growth depends on their rates of investment. This is a plausible mechanism, but it explains why incumbents may invest in small improvements of their own technologies, which is a trivial activity, and not why they may directly compete against outsiders to obtain radical innovations, which is the key issue.

The alternative explanation for innovation by incumbents that we embrace in this work does not rely on technological advantages or exogenous market structures, but is based on a pure strategic advantage of the incumbents in patent races with endogenous market structures. Gilbert and Newbery (1982) were the first to show that in a deterministic contest (an auction for patents), an incumbent finds it profitable to invest just 
enough to deter any investment by any outsider. However, this is not necessarily the case in the presence of a more realistic contest under uncertainty with barriers to entry. We show that in such a contest, an incumbent leader does not usually deter entry, but always finds it profitable to invest more than any outsider as long as entry is endogenous. The model is in the tradition of the recent works on endogenous market structures and market leadership, ${ }^{2}$ and shows the crucial role of entry pressure on the different behaviour of leaders and followers. First, we show that an increase in the number of investors reduces profitability and therefore the investment of each firm: therefore the endogenous entry threat tends to reduce the R\&D intensity of each firm. Moreover, in a symmetric contest, an incumbent monopolist has lower incentives to invest in R\&D because in case of innovation it replaces itself: this is the Arrow effect, which leads to zero investment by the incumbent in case of endogenous entry. Then we show that the outcome changes radically when the incumbent is also the leader of the contest for the innovation, which is often reasonable because of its strategic advantage in the market. The incumbent leader exploits its first mover advantage to invest more than the other firms. The intuition has to do with the impact of its investment on entry: a small investment attracts large entry and makes it likely that another firm will replace the incumbent, while a commitment to a large investment has the double advantage of reducing entry and increasing the chances of an innovation. ${ }^{3}$ We also show that these theoretical results are robust to different model specifications; in particular, they hold in general patent races (see Etro, 2004, 2008) and in models of preliminary investment in cost reducing $\mathrm{R} \& \mathrm{D}$ as a strategic commitment for the competition in the market (see Etro 2006). ${ }^{4}$

We bring to the data the two basic predictions of our theoretical investigations: the R\&D intensity of the average firm is lower when there is an endogenous entry threat, and the $R \& D$ intensity of the incumbent leader is larger than that of the average firm when there is an endogenous entry threat. ${ }^{5}$ We test these hypotheses through a Tobit model for R\&D intensity. Our empirical investigation is based on a unique dataset on the German manufacturing sector, the Mannheim Innovation Survey from 2005 conducted by the Centre for European Economic Research (ZEW), which includes a wide number of firmlevel data with a special focus on innovation. The main problem in testing hypotheses concerning market structures is that the definitions of markets, their leaders and entry conditions are usually based on statistical indexes (for instance on market concentration and dominance) with limited explanatory power, or on discretionary evaluations by external observers (for instance on who is the leader in the relevant market). A novel aspect of our empirical approach is the fact that the same firms provide a subjective view on the market in which they operate and its leadership, on the entry conditions and on the key determinants of R\&D intensity. Rather than determining arbitrarily the size and composition of a market, assigning a degree of entry intensity in a discretionary way and assigning a status of leadership on the basis of possibly arbitrary assumptions, using the survey results we allow the firms to identify the size of their main market, the existence of an endogenous threat of entry in the market and the identity of the leader in the market. We also perform robustness tests concerning the potential reverse causality between R\&D and entry threats using IV regressions and a number of exogeneity tests. Our main predictions are strongly supported by the empirical evidence: entry pressure reduces the average investment per firm, but incumbent leaders invest more than other firms when there is the pressure of a strong threat of entry.

These results can be interpreted as a first attempt to test the main predictions of the endogenous market structures approach, which analyses the role of firms in markets 
where entry is endogenous. In this case, the behaviour of incumbent leaders is radically different depending on the entry conditions, and the conclusions of the cited approach appear to be confirmed empirically. At a policy level, the results suggest also that we may have to change our way of looking at persistent dominance in technologically advanced markets: this may be the result of strong competitive pressures rather than of market power, at least in those markets in which there are no barriers to innovation for the outsiders.

The article is organized as follows: Section I describes the theoretical model and derives the empirical prediction, Section II provides the empirical evidence and Section III concludes.

\section{A MODEL OF R\&D INVESTMENT}

The aim of this section is to provide theoretical motivation for our testable predictions. With this purpose in mind, we first develop the simplest model that leads to our main results, and then sketch other theoretical frameworks that support the same predictions.

Let us consider a simple contest between $n$ firms to obtain a drastic innovation that provides a flow of profits $V$ for the winner and generates no gains for the losers. ${ }^{6}$ Each contestant $i$ bears fixed costs $F$ and invests a fraction of its revenues in R\&D. The cost of investment is assumed to be an increasing and convex function of the $R \& D /$ sales ratio $z_{i} \in[0,1]$, and is normalized to generate a probability of innovation $z_{i}$. More precisely, we assume that the cost of the $\mathrm{R} \& \mathrm{D}$ activity is quadratic, that is, $d z_{i}^{2} / 2$, where the constant $d$ parametrizes the marginal cost of investing in R\&D. ${ }^{7}$ We can think of the fixed cost as the investment necessary to be engaged in R\&D activity (e.g. build a laboratory), and of the rate of investment as related to the variable cost (e.g. allocating researchers and capital to the laboratory). To focus on interesting cases, we assume $F<d / 2$ and $V \in(\sqrt{2 d F}, d)$ : these assumptions guarantee that at least one firm invests a part of its revenues in R\&D.

If multiple firms innovate at the same time, then competition in the market drives their profits to zero, therefore the contest has a winner only in the case of a single innovator. Summing up, the expected profit function of a generic contestant $i$ is

$$
\Pi_{i}=z_{i} \prod_{j=1, j \neq i}^{n}\left(1-z_{j}\right) V-\left(\frac{d z_{i}^{2}}{2}+F\right)
$$

where the first term is the expected gain from innovating, and the second term is the cost of the R\&D investment. The probability of winning the contest for firm $i$ is the probability of innovating $z_{i}$ multiplied by the probability that no other firm (including the incumbent) innovates, $\prod_{j \neq i}\left(1-z_{j}\right)$. With this probability, the contestant obtains the award $V$.

\section{Entry in the contest}

In this subsection we evaluate the impact of entry on the investment level of each firm engaged in the contest in a symmetric Nash equilibrium. Let us start from the case in which the number of firms $n$ is exogenous. The first-order condition for the investment of each firm can be written as follows in a symmetric equilibrium: 


$$
z=\frac{(1-z)^{n-1} V}{d}
$$

Notice that a monopolist would invest $z=V / d<1$ under our regularity assumptions. Total differentiation of the equilibrium condition provides

$$
\frac{\mathrm{d} z}{\mathrm{~d} n}=-\frac{z(1-z) \log (1 /(1-z))}{1+(n-2) z}<0
$$

More firms imply a lower rate of investment for each firm (though aggregate investment may increase, of course). Moreover, the rate of investment of each firm is increasing in the value of the innovation $V$ and decreasing in the marginal cost of the investment (in $d$ ).

Since entry reduces the expected gross profits, ${ }^{8}$ we can immediately characterize the endogenous market structure. Firms enter until the following zero profit condition holds:

$$
z(1-z)^{n-1} V=\frac{d z^{2}}{2}+F
$$

Combining (1) with (2) and solving for $z$, when the number of firms is high enough to dissipate all profits, the investment of each entrant is

$$
z=\sqrt{\frac{2 F}{d}} .
$$

If we substitute this equilibrium investment in (2), take logs and solve for $n$, then we obtain the endogenous number of firms:

$$
n=1+\frac{\log (V / \sqrt{2 d F})}{\log [1 /(1-\sqrt{2 F / d})]} .
$$

To exclude the case of a natural monopoly and insure that $n \geq 2$, we adopt the additional assumption $V>\sqrt{2 d F} /(1-\sqrt{2 F / d})$. The endogenous market structure depends on technological conditions and on the value of the innovation. First, an increase in the value of the innovation $V$, which may be due to stronger intellectual property rights or a larger market size, increases the number of investors, even if this happens in a less than proportional way-see (3). The reason is that a larger gain from innovating attracts more firms but strengthens rivalry between them so as to reduce the rate of future entry. At the same time, notice that the investment of each firm is now independent of the size of the innovation: total R\&D in the market increases through an increase in the number of investors only. Second, an increase in the fixed cost $F$ reduces entry, which in turn allows a smaller number of firms to invest more and expect larger gross revenues to cover the larger fixed costs. ${ }^{9}$ Finally, a larger marginal cost of the R\&D investment $d$ has a negative impact on the investment of each firm. We can think of the marginal cost of investment as an inverse function of the human resources of the firm: a larger pool of workers reduces the marginal cost of research and therefore corresponds to a lower $d$. Accord- 
ingly, the equilibrium investment is increasing in the size of the firm's labour force and is increasing in a less than proportional way.

For our purposes, it is important to summarize the reaction of the rate of investment $z$ when the number of firms increases from one to the maximum number of firms that is consistent with non-negative profits, that is, the endogenous number of firms: R\&D investment decreases with entry and is minimal with endogenous entry. Finally, one can show that the equilibrium tends to be associated with excess entry and a suboptimal rate of investment; in particular, if the social value of the innovation is the same as its private value $V$, then the optimal allocation of resources requires a lower number of firms investing more (relative to the equilibrium). ${ }^{10}$

\section{The role of incumbents}

We now study innovation in markets where there is an incumbent firm that is the current monopolist in the market (for instance because of a patent on the existing leading technology). This incumbent maintains its profits $\pi>0$ in case no one innovates. Therefore the expected profits of the incumbent are

$$
\Pi_{I}=z_{I} \prod_{j \neq I}^{n}\left[1-z_{j}\right] V+\left(1-z_{I}\right) \prod_{j \neq I}^{n}\left[1-z_{j}\right] \pi-\frac{d z_{I}^{2}}{2}-F,
$$

where the index $I$ stands for incumbent. The profits of the outsiders remain the same as before. As noticed by Arrow (1962), the incentives of the incumbent to invest are lower than for the outsiders. To verify this, we will consider a Nash equilibrium in the choice of R\&D investment between the incumbent and the outsiders, distinguishing between the case with no entry pressure, that is, with a fixed number of outsiders, and the case with endogenous entry pressure.

First, assume no entry pressure. With a fixed number of outsiders $n$, the equilibrium first-order conditions for the incumbent and the outsiders are

$$
z_{I}=\frac{(1-z)^{n-1}(V-\pi)}{d} \quad \text { and } \quad z=\frac{(1-z)^{n-2}\left(1-z_{I}\right) V}{d}
$$

which provides $z_{I}<z$ : outsiders always invest more than the incumbent as long as $\pi>0$. This leads also to lower profits from the contest for the incumbent compared to the outsiders.

Now consider endogenous entry pressure. Under free entry, the number of firms increases until the expected profits of the outsiders are zero. As a consequence, the incumbent is better off withdrawing from the contest and invests zero: this is the traditional Arrow (1962) effect in action.

\section{The role of incumbent leaders}

When the incumbent has a first mover advantage and can choose its investment before the entry of the outsiders (i.e. is an incumbent leader), the incentives to invest are radically changed. We will now examine this case, first when the number of outsiders is exogenous, and then when it is endogenous. 


\section{No entry pressure}

Consider a Stackelberg equilibrium between an incumbent and a fixed number of outsiders $n$. In this case, there would be two effects to determine the size of the investment of the incumbent leader. On one side, the Arrow effect would lead to a lower investment compared to the followers because the incumbent leader would have less to gain from innovating. On the other side, we would have a Stackelberg effect, which works in the opposite direction in this framework characterized by strategic substitutability. In general, incumbent leaders may invest more, less or approximately the same as the outsiders in markets where the number of firms is given. Nevertheless, as long as $\pi$ is high enough, the first effect would prevail and the incumbent leader would invest less than the average follower. For instance, with $d=1$ and $n=2$, in case of interior solutions, we have

$$
z=\frac{V \pi+(1-V) V-V^{3}}{1-2 V(V-\pi)} \quad \text { and } \quad z_{I L}=\frac{V \pi+(1-V)(V-\pi)}{1-2 V(V-\pi)}
$$

where the index $I L$ stands for incumbent leader. The Arrow effect prevails on the Stackelberg effect whenever $\pi>V^{3} /(1-V) .^{11}$

\section{Endogenous entry pressure}

Now let us consider a Stackelberg game with endogenous entry where the incumbent is leader in the choice of its investment $z_{I L}$. Then entry occurs, and finally all the outsiders simultaneously choose their investment.

Let us start from the last stage to characterize the equilibrium investment of the outsiders for a given number $n$ and a given investment by the incumbent $z_{I L}$. The first-order conditions can be written as follows in a symmetric equilibrium:

$$
z=\frac{(1-z)^{n-2}\left(1-z_{I L}\right) V}{d}
$$

Again, R\&D investment per firm is a decreasing function of the number of firms. In the second stage, firms enter until the following zero profit condition holds:

$$
z(1-z)^{n-2}\left(1-z_{I L}\right) V=\frac{d z^{2}}{2}+F
$$

Combining these two equations, the rate of investment of each entrant becomes

$$
z=\sqrt{\frac{2 F}{d}}
$$

which is exactly the same as before: the presence of a leader does not affect what the other active firms do. If we substitute this equilibrium investment in (4), take logs and solve for $n$, we obtain the endogenous number of outsiders as a function of the investment of the incumbent: 


$$
n\left(z_{I L}\right)=2+\frac{\log \left[\left(1-z_{I L}\right) V / \sqrt{2 d F}\right]}{\log [1 /(1-\sqrt{2 F / d})]}
$$

Clearly this number is at least 2 if $z_{I L}$ is small enough. More precisely, since $n\left(z_{I L}\right)=2$ requires $\log \left[\left(1-z_{I L}\right) V / d z\right]=0$, entry occurs if $z_{I L}<1-\sqrt{2 d F} / V$. Notice that in case of small fixed costs, say close to zero, the equilibrium rate of investment (5) is close to 0 , and the entry deterring rate of investment is close to 1 : in such a case, entry deterrence is a very costly strategy. In this case, $R \& D$ intensity is still reduced by entry.

We now turn to the behaviour of the incumbent leader in the first stage. As long as the investment of the leader $z_{I L}$ is small enough to allow entry of some followers, each one of the followers invests as in (5), and the number of firms is given by (6). The incumbent leader can choose $z_{I L} \in(0,1-\sqrt{2 d F} / V)$ to maximize the expected profits:

$$
\Pi_{I}=z_{I L}(1-z)^{n-1} V+\left(1-z_{I L}\right)(1-z)^{n-1} \pi-\frac{d z_{I L}^{2}}{2}-F
$$

given the above equilibrium expressions for $z$ and $n\left(z_{I L}\right)$. In particular, solving (4) for $(1-z)^{n-1} V=d z(1-z) /\left(1-z_{I L}\right)$, using $z=\sqrt{2 F / V}$, and substituting in the expected profits of the incumbent leader, we have

$$
\Pi_{I}=d\left[\left(\frac{z_{I L}}{1-z_{I L}}+\frac{\pi}{V}\right) \sqrt{\frac{2 F}{d}}\left(1-\sqrt{\frac{2 F}{d}}\right)-\frac{z_{I L}^{2}}{2}\right]-F
$$

Evaluating the derivative with respect to $z_{I L}$ at $z_{I L}=z$, we obtain

$$
\frac{\partial \Pi_{I}}{\partial z_{I L}}=d\left[\frac{1}{(1-z)^{2}} \sqrt{\frac{2 F}{d}}\left(1-\sqrt{\frac{2 F}{d}}\right)-z\right]=\frac{2 F}{1-\sqrt{2 F / d}}>0
$$

which shows that it is always optimal for the incumbent leader to increase the rate of investment beyond that of the followers. However, the optimal strategy may be an interior solution or a corner solution.

The first-order condition for an interior solution is

$$
\sqrt{\frac{2 F}{d}}\left(1-\sqrt{\frac{2 F}{d}}\right)=z_{I L}\left(1-z_{I L}\right)^{2}
$$

and the second-order condition is satisfied only for $z_{I L}<1 / 3$. For a sufficiently small fixed cost, entry deterrence is too costly and the interior solution characterizes the equilibrium: the smallest root of this cubic equation provides the equilibrium investment of the incumbent leader. Therefore when the fixed cost of entry is small enough, the incumbent leader does not deter entry, but invests more than any outsider. Contrary to the entry deterrence rationale for innovation by leaders advanced by Gilbert and Newbery (1982), ${ }^{12}$ here both leaders and outsiders invest in R\&D, but leaders invest more. 
Of course, when the fixed entry cost is high enough, entry deterrence can be optimal. In particular, when $F$ is large enough and/or $V$ is small enough, the expected profits are always increasing in the investment of the leader in the relevant range, and we have a corner solution such that no outsider enters. The entry-deterring investment of the incumbent leader is

$$
z_{I L}=1-\frac{\sqrt{2 d F}}{V}
$$

which is larger than $z$ under our assumption $V>\sqrt{2 d F} /(1-\sqrt{2 F / d})$. Therefore in all cases the incumbent leader invests more than any outsider.

When the incumbent monopolist is the leader in the competition for the innovation, the Arrow effect disappears, because the choice of the monopolist is independent of the current profits. ${ }^{13}$ Notice that the entry deterring rate of investment of the leader is increasing in the expected flow of profits $V$ (more expected profits require a larger investment to deter entry of the outsiders). Moreover, the investment is still decreasing in $d$, and is now decreasing in the fixed cost of entry of the other firms (which reduces the investment needed to deter entry). The intuition for the larger investment of the incumbent leader has to do with the impact of its investment on entry: a small investment attracts large entry and makes it likely that another firm will replace the incumbent, while a commitment to a large investment has the double advantage of reducing entry and reducing the chances of an innovation by others.

The interest of this result emerges when we compare it to the case in which the incumbent has no first mover advantage. In such a case, the standard Arrow effect leads to the opposite result: the incumbent does not invest at all, and only the outsiders invest and possibly innovate. Summing up, there are two conditions under which a firm always invests more than others in R\&D: (1) this firm is the incumbent leader; (2) there is an endogenous entry threat in the market.

The main empirical predictions of our simple contest are not model-specific, and they can be found in other general models of investment in R\&D. To convince the reader of this, we will briefly provide a couple of examples.

\section{A general patent race}

A wide literature on R\&D investments (started by Dasgupta and Stiglitz 1980) ${ }^{14}$ has studied patent races where the rate of investment $z_{i}$ generates innovations according to a Poisson process with an arrival rate given by a function $h\left(z_{i}\right)$ eventually exhibiting decreasing returns to scale, so that the expected value of innovating for an average firm is $h\left(z_{i}\right) V /$ $\left[r+\sum h\left(z_{j}\right)\right]$, where $r$ is the interest rate. In such a case, one can verify that entry always reduces the investment of the average firm (this is due to strategic substitutability), and Etro $(2004,2008)$ has shown that when entry is endogenous, the incumbent leader always invests more than any other single firm. In case of linear variable costs of investment $d z_{i}$, the first-order conditions for the rate of investment of the average firm $z$ and of the incumbent leader $z_{I L}$, and the endogenous entry condition, lead to the following equilibrium equations (Etro 2008):

$$
h^{\prime}(z) \frac{V-F-z}{V}=h^{\prime}\left(z_{I L}\right)=\frac{d h(z)}{z+F} .
$$


From these conditions one can verify that $z_{I L}>z$. Such an outcome confirms the validity of the main empirical predictions of our basic model.

\section{Strategic investment in $R \& D$}

Similar results have been developed in models of R\&D spending as a strategic investment preliminary to the competition in the market. In these models, R\&D spending per firm is typically decreasing with the number of firms because more competition reduces profits and sales, which reduces the incentives to invest: this confirms our earlier results on the negative relation between entry and investment. Moreover, the investment of the incumbent leaders can be radically different according to whether or not entry is endogenous. In models of competition in prices, Etro (2006) has shown that market leaders should spend less than the other firms in R\&D investments in cost reductions when the number of firms is exogenous, but they should spend more when entry is endogenous. Under competition in quantities, the leader would generally spend more than the followers on cost reductions under both entry conditions; nevertheless, also in such a case, an incumbent facing endogenous entry would invest more when it has a first mover advantage, not only in absolute amount but also relative to revenue. To verify the last result, let us briefly consider a model of Cournot competition with inverse demand $p=a-X$. All firms have a constant marginal cost $c$ except the incumbent, which can invest $k$ in $\mathrm{R} \& \mathrm{D}$ to reduce its marginal cost to $c(k)=c-\sqrt{k / d}$, with $d>1$.

In a symmetric equilibrium for the choice of investment $k$ and production $x_{I}$ for the incumbent and $x$ for the other firms, one can verify that R\&D investment decreases with the number of firms. When entry is endogenous, the equilibrium price is $p=c+\sqrt{F}$, and the incumbent invests $k=d F /(2 d-1)^{2}$ and produces $x_{I}=2 d \sqrt{F} /(2 d-1)>x=$ $\sqrt{F}$. The rate of investment $z_{I}=\mathrm{R} \& \mathrm{D} /$ sales $=k / p x_{I}$ can be calculated as follows:

$$
z_{I}=\frac{\sqrt{F}}{2(2 d-1)(c+\sqrt{F})} .
$$

When the incumbent can precommit to an investment in $\mathrm{R} \& \mathrm{D}$, it will choose a larger investment $k=d F /(d-1)^{2}$ without affecting the equilibrium price, but expanding its own production $x_{I}=d \sqrt{F} /(d-1)$ and reducing the number of entrants. The equilibrium rate of investment becomes

$$
z_{I L}=\frac{\sqrt{F}}{(d-1)(c+\sqrt{F})},
$$

which satisfies $z_{I L}>z_{I}$. It is remarkable that this result is now presented in terms of the $\mathrm{R} \& \mathrm{D} /$ sales ratio, which is exactly the dependent variable used in our empirical analysis. More generally, as shown also by Maci and Žigić (2011) and Kováč et al. (2010), the leadership always generates strategic overinvestment in $R \& D$ relative to sales when entry is endogenous.

\section{Testable predictions}

Our overview of simple and general theoretical models of the incentives to invest in R\&D emphasizes two conclusions that appear robust to alternative modelling specifications. They can be summarized as follows. 
Hypothesis 1. R\&D intensity of the average firm decreases with entry and is lower when there is an endogenous entry threat compared to when there is not.

Hypothesis 2. R\&D intensity of the incumbent leader is larger than the investment of the average firm when there is an endogenous entry threat.

The first hypothesis suggests a negative relation between the threat of entry perceived by the firms and their rate of investment in $\mathrm{R} \& \mathrm{D}$, and it derives from the strengthening of competition for the market induced by entry. The second hypothesis is our main interest because it is in radical contrast with the Arrow view of the incumbents as firms investing less than the other firms in R\&D. According to our models, these incumbents should invest more than the other firms if they are leaders and face a strong threat of entry pressure.

\section{EMPIRICAL TEST}

In this section, we perform an empirical test on whether actual firm-level investment data support our hypotheses derived from the theoretical framework.

\section{Data sources}

We use data from the Mannheim Innovation Panel (MIP) from the year 2005. This innovation survey has been conducted by the Centre for European Economic Research (ZEW), Mannheim. The ZEW has conducted the survey since 1992, and it represents the German part of the EU-wide harmonized Community Innovation Survey (CIS). It follows the Eurostat/OECD guidelines for collecting innovation data, which are documented in the so-called Oslo Manual (see OECD and Eurostat 1997). Readers not familiar with the survey are referred to the summary reports, e.g. Eurostat $(2004,2008)$. The MIP data constitute a representative sample of the German manufacturing sector as well as business-related services. For our study, we focus on the manufacturing sector. The 2005 spell of the MIP included some unique questions allowing us to model entry threats and to identify leaders.

The database has a cross-sectional structure, but the questionnaire collects information generally for the years 2002 to 2004 . The quantitative variables, such as R\&D investment, capital, employment, sales, etc., are surveyed for a certain year. For instance, R\&D investment is collected only for the year 2004. Other information that we use as controls are, however, collected for the two years 2003 and 2004, so that we can make use of lagged controls to avoid direct simultaneity bias in the regressions. Qualitative information, such as the competitive situation in a firm's main market, the firm's competitive position, etc., are collected through one question each referring to the time period 20024. We will use the qualitative information to construct variables on incumbency and entry threats during this period, and argue that the situation between 2002 and 2004 will have an impact on strategic investment behaviour in 2004.

The dependent variable of our analysis is the R\&D intensity in the year 2004 at the firm level. The intensity is defined as $R D I N T_{i}=R \& D_{i} / S A L E S_{i} \times 100$.

The most important right-hand side variables are the entry threat and the leadership position. An innovative aspect of our empirical approach is given by the fact that the same firms provide a subjective view on these two factors: rather than assigning a degree 
of entry intensity in a discretionary way or assigning a status of leadership on the basis of arbitrary variables, we allow the firms to identify the existence of an endogenous threat of entry in the market and the identity of the leader in the market.

The survey asked for several characteristics about the competitive situation in firms' main product markets in the time period 2002-4. In particular, firms were asked to indicate if a list of six statements about the firms competitive environment apply to their situation or not. The response was based on a four-point Likert scale, from 'applies strongly' to 'does not apply at all'. One of those six statements considered entry pressure, and was phrased as follows: 'Position in the market is highly threatened by entry of new competitors'. Thus our variable of entry threat, ENTR $Y_{i}$, is an ordinal variable taking values from 0 to 3 , where 3 indicates that the respondent firm strongly agreed with the statement that its market position is highly threatened by entry. When this is the case, we conjecture that entry in the industry where the firm is active can be regarded as endogenous; when the firm does not consider the threat of entry as present in its industry, this is regarded as one with an exogenous number of firms. As found in the theoretical framework (Hypothesis 1), we expect a negative sign of $\operatorname{ENTR} Y_{i}$ in the regressions for the average R\&D intensity.

The theoretical definition of a market leader is associated with a strategic first mover advantage, but a more general definition can be based on the leading strategic position of the firm compared to its main competitors. Therefore our incumbent variable is defined through a question on a firms' position compared to its main competitors. The respondents indicated if their competitors in their main market are larger, smaller, similar size, or larger and smaller than their firm. ${ }^{15}$ An incumbent leader in our analysis is identified by an indicator variable $L E A D E R_{i}$ describing a firm that perceives itself as larger than the competitors in its main product market. The main advantage of this survey information is that the firms themselves identify their relevant market. Therefore it is irrelevant whether the company is only domestically or also internationally active. The companies' managers have to assess their main competitors, whoever they are and wherever they come from. This would not be possible if, for instance, a concentration index or market share data were used, as such information is typically available only at national levels.

While we expect that entry has a negative impact on the investment of each single firm, the theoretical framework shows that leaders choose to invest more than other contestants if their market is threatened by entry (Hypothesis 2). We capture this by an interaction term of leadership and entry $\left(L E A D E R_{i} \times E N T R Y_{i}\right)$.

As outlined in the theoretical model, it is desirable to control for employment and capital requirement. We include firms' employment in $t-1\left(E M P_{i, t-1}\right)$ as well as capital intensity $\left(K A P I N T_{i, t-1}\right)$ measured as fixed assets divided by employment in the empirical model to account for such impacts on investment decision. For the size of the employment we expect a positive and concave relation on the basis of our theoretical work. Concerning the role of capital intensity, we do not have strong priors on the sign of the coefficient. We also control for the Herfindahl index (HHI) of concentration of the industry where the firm is active $\left(H H I_{i, t-1}\right)$. These data are obtained from the German Monopolies Commission, which biannually publishes the official German industry concentration statistics. ${ }^{16}$ The Herfindahl index accounts for domestic market structure. We also use the lagged import ratio at the industry level to control for competitive pressure from abroad $\left(\right.$ IMPORT $_{i, t-1}=$ imports $_{i, t-1} /\left(\operatorname{imports}_{i, t-1}+\right.$ domestic $\left._{\left.\text {production }_{i, t-1}\right)}\right)$.

In addition, we control for some other factors that might influence firms' R\&D investment. For example, different corporate governance structures may have an effect on the dependent variable either through the access to capital or through heterogeneity in 
management objectives. We use a dummy variable $G R O U P_{i}$, indicating whether a firm is associated with a group of companies. Such firms might have better access to capital through the parent company and thus may innovate more than stand-alone companies. In addition, we take into account whether the parent company is a foreign enterprise $(\text { FOREIGN })_{i}$.

Among others, Aghion and Howitt (1992) and Acemoglu and Linn (2004) suggest that efforts to innovate increase with market size. Therefore we also control for the size of the market by using the total sales volume at the three-digit NACE industry level (MAR$\left.\operatorname{KETSIZE}_{i, t-1}\right)$. These data were also obtained from the German Monopolies Commission. We use the lag of market size in the regressions to avoid a simultaneity bias.

Finally, we use 14 industry dummies to control for unobserved heterogeneity in investment across industries. The industries are Food, Textiles/Leather, Paper/Wood/ Furniture, Publishing/Printing, Chemicals, Rubber, Glass/Ceramics, Metal Production, Metal Products, Machinery, Electronics, Information \& Communication Technology, Instruments/Optics and Vehicles. The list of controls is complemented by state dummies. Germany is divided into 16 states, the 'Länder'. As some of those are very small, we aggregated them into 12 different regions.

Table 1 shows the descriptive statistics of core variables used in the upcoming regression analysis. In total, our sample consists of 1857 firm-level observations. The average R\&D intensity of firms is about $2.3 \%$, and average firm size amounts to 307 employees in the sample. $8 \%$ of all firms are classified as incumbent leaders.

\section{Patent stocks, intellectual property rights and unobserved firm heterogeneity}

A main determinant of the investment in R\&D is the degree of protection of the intellectual property (IP) rights associated with the innovations that each firm can obtain. It is

TABLE 1

DESCRIPTIVE STATISTICS

\begin{tabular}{|c|c|c|c|c|}
\hline Variable & Mean & S.D. & Min & Max \\
\hline$R D I N T_{i t}$ & 2.204 & 5.015 & 0 & 38.914 \\
\hline$E M P_{i, t-1} / 1000$ & 0.298 & 1.237 & 0.001 & 36.761 \\
\hline$K A P I N T_{i, t-1}$ & 0.078 & 0.090 & 0.001 & 0.861 \\
\hline$L E A D E R_{i t}$ & 0.080 & 0.271 & 0 & 1 \\
\hline$E N T R Y_{i t}$ & 1.537 & 0.851 & 0 & 3 \\
\hline$H H I_{i, t-1} \times 1000$ & 36.778 & 61.022 & 3.15 & 650.17 \\
\hline $\operatorname{PSTOCK}_{i, t-1} /\left(E M P_{i, t-1} / 1000\right)$ & 8.864 & 26.906 & 0 & 222.447 \\
\hline IPPROTECTION $_{i t}$ & 0.201 & 0.401 & 0 & 1 \\
\hline$G R O U P_{i t}$ & 0.602 & 0.489 & 0 & 1 \\
\hline$F O R E I G N_{i t}$ & 0.112 & 0.315 & 0 & 1 \\
\hline$I M P O R T_{i, t-1}$ & 0.226 & 0.121 & 0 & 1 \\
\hline $\ln (M S I Z E)_{i, t-1}$ & 10.216 & 0.995 & 4.620 & 11.792 \\
\hline \multicolumn{5}{|l|}{ IV candidates } \\
\hline$M E S_{t-1}$ & 0.079 & 0.166 & 0.009 & 2.102 \\
\hline$N E W K A P_{i t}$ & 0.015 & 0.013 & 0.001 & 0.134 \\
\hline$\triangle M A T P R I C E \%_{i t}$ & 0.064 & 0.278 & -3.082 & 5.556 \\
\hline
\end{tabular}

Notes

1857 observations. Industry dummies and region dummies omitted. 
difficult to measure the degree of protection of the intellectual property rights at the firm level, but we can proxy this with two measures.

First, we use stock of patents at the firm level. In particular, the differences between firms in the size of the patent portfolio can be associated with the differences in the degree of expected protection of the innovations of the firms, therefore we expect a positive correlation between R\&D intensity and the patent stock. Moreover, the introduction of this important control variable allows us to obtain a robustness check that might account for unobserved heterogeneity even in the absence of panel data, as the number of patents taken out in the past should also proxy past R\&D efforts.

Our measure of the patent stock at the firm level accounts for all patent applications from 1978 onwards. In particular, we compute the patent stock using the perpetual inventory method for each firm. The survey data has been merged with the database from the German Patent Office, which covers all patents filed at both the German and the European Patent Office since 1978. We follow the common practice in the literature and impose a rate of obsolescence of $15 \%$ per year when computing the patent stock (see, for example, Griliches and Mairesse 1984). Including such a rate of obsolescence implies, quite realistically, that knowledge loses its relevance similarly as capital depreciates over time. The variable $P S T O C K$ is given by

$$
\text { PSTOCK }_{i t}=(1-\delta) P S T O C K_{i, t-1}+P A_{i t},
$$

where $\delta=0.15$, and $P A_{i t}$ denotes patent applications of firm $i$ in year $t$. We set the initial patent stock in year 1978 to zero for all firms. Since we use data from 2002-4 in our regressions, the bias arising from a zero starting value will have disappeared due to the included depreciation rate $\delta$.

Second, we use a variable reflecting the appropriability conditions in the industry. In the survey, firms were asked to what extent patents are an important tool for protecting intellectual property in their business. We create a dummy variable IPPROTECTION that takes unit value if the firm rated patents as highly important in their industry. This should capture the appropriability conditions in the firm's main market, and we expect that the estimated coefficient will be positive, that is, it reflects higher incentives for conducting R\&D.

\section{Potential reverse causality between $R \& D$ and entry threat}

In our empirical investigation, we proxy the threat of entry in the market where each firm is active with the perception of the firm as collected in our survey data. This avoids an arbitrary decision on whether a market is characterized by endogenous entry as opposed to being limited to an exogenous number of firms. A possible concern of our approach relies in the independence of our entry variable from the dependent variable, R\&D intensity. Reverse causality could affect our results: in principle, it is possible that current R\&D leading to a future technological advantage makes firms perceive the entry threat as less severe, while on the other hand, if firms are not research active and neglect the development of new processes and products, entry may appear as a quite realistic threat. To test the possibility of a reverse relationship, we experimented with a number of candidates for instrumental variables as outlined in the following paragraphs.

To find instrumental variables that explain our entry variable but not the R\&D intensity variable, we need to look at the key element determining entry pressure, the difference 
between the expected gross profits in the market and the fixed costs of entry. There is a well-developed theoretical and empirical literature on the so-called barriers to entry. The empirical studies on entry barriers address the question of natural barriers, like sunk costs of entry determining scale economies, and on the other side strategic barriers, for instance excess capacity, limit pricing, product differentiation and innovative activity.

It is not simple to find a measure of the fixed costs of entry. Sutton (1998) uses the size of the median plant in an industry as a proxy for minimum efficient scale, and therefore for the size of the costs of entry. In other studies, variants of size measures are used, but most studies rely on observed size as it is very difficult to get information on the minimum efficient size required by the technology used. ${ }^{17} \mathrm{We}$ have information on total industry sales and the number of firms active in an industry. This information is taken from official statistics and measured at a detailed industry level (NACE three-digit level). ${ }^{18}$ The ratio, industry sales per firm is applied as a proxy for minimum efficient scale and enters the regressions as a lagged value $\left(M E S_{t-1}\right)$.

Furthermore, we use another proxy for sunk cost of entry that has been suggested by Gschwandtner and Lambson (2012). This variable is the amount of new capital expenditure (investment) per employee in the industry (denoted by $N E W K A P_{i t}$ ). Gschwandtner and Lambson (2012) argue that the higher the new capital by firms in an industry, the higher the (unobserved) sunk costs are to be expected. Thus we would presume a negative relationship between this variable and entry. We compute this measure at the three-digit NACE industry level. We expect this instrument to be relevant and also exogenous in our model, as the expected sunk cost occurring when entering an industry should not depend on an individual firm's R\&D efforts.

Another factor that can affect profitability and entry is changes in production cost in an industry, as entry decisions are likely to be affected by cost conditions and in particular by recent changes. If, for some reason, cost increases get large and production conditions worsen, prices will in most cases increase, and this in turn leads to lower demand. In such a situation entry is unattractive. Consequently, we consider cost of raw and intermediate materials as a candidate for an instrumental variable explaining entry. As we do not have access to a price indicator at the industry level concerning material input, we compute the statistic below from our sample firms and aggregate it to the industry level. We use the change in material cost spent per employee over time at the industry level. Thus this measure proxies the changes in material cost required per workplace in the production process. The variable at the firm level is computed as

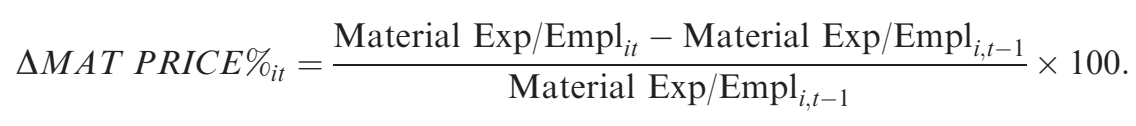

This measure is then averaged at the three-digit NACE industry level. If input relations regarding material and employment remain constant over the two included periods, this is equivalent to changes in material prices. Increasing costs are, of course, expected to discourage entry. Again, we expect that this measure is also exogenous in our model as a firm's R\&D efforts should not affect the change in material prices at the industry level.

\section{Econometric analysis}

As not all firms invest in R\&D, we estimate Tobit models that take account of the left censoring of the dependent variable. The Tobit model to be estimated can be written as 


$$
\operatorname{RDINT}_{i}^{*}=X_{i} \beta+\varepsilon_{i},
$$

where $R D I N T_{i}^{*}$ is the unobserved latent variable. The observed dependent variable is equal to

$$
\operatorname{RDINT}_{i}= \begin{cases}\operatorname{RDINT}_{i}^{*} & \text { if } X_{i}^{\prime} \beta+\varepsilon_{i}>0 \\ 0 & \text { otherwise. }\end{cases}
$$

$X_{i}$ represents the matrix of regressors, $\beta$ represents the parameters to be estimated, and $\varepsilon_{i}$ represents the random error term. In our basic specification, $X_{i}$ includes $E M P_{i, t-1}$, $E M P_{i, t-1}^{2}, K A P I N T_{i, t-1}, L E A D E R_{i t}$ and $E N T R Y_{i t}$, as well as 13 industry dummies. In further models, we add the interaction term $L E A D E R_{i t} \times E N T R Y_{i t}$ and $P S T O C K_{i t}$ to control for further heterogeneity.

We first consider homoscedastic regressions, and subsequently test for heteroscedasticity as coefficient estimates may be inconsistent if the assumption of homoscedasticity is violated in Tobit models. In order to estimate heteroscedastic Tobits, the homoscedastic variance $\sigma$ is replaced with $\sigma_{i}=\sigma \exp \left(Z_{i}^{\prime} \alpha\right)$ in the likelihood function (see Greene 2003, pp. 768-9). We consider groupwise multiplicative heteroscedasticity by using a set of five size dummies (based on employment) and the industry dummies in the heteroscedasticity term.

Tables 2 and 3 show the regression results for homoscedastic and heteroscedastic models, respectively. In the homoscedastic Tobit Model I, we find that R\&D investment decreases as the threat of entry increases. The leaders' investment does not differ from that of the outsiders. When we add the interaction term of leadership and entry threat (see Model II), however, interesting differences occur. While the leader dummy is still insignificant, we now find that leaders who are faced by potential entry invest more than outsiders.

The results remain robust when we control for prior R\&D using the patent stock and also for the appropriability conditions in the industry (Model III). Both the patent stock and the dummy on IP protection are highly significant and positive, confirming that firms receiving stronger protection of IP rights through patents tend to invest more, and firms that (successfully) conducted R\&D in the past as reflected by the patent stock will also invest more in the current period. One could also read this result as contradicting the view for which firms with a lot of patents would be less innovative and use their patent portfolio to jeopardize further investments in R\&D.

With respect to the other covariates, we find a positive and concave relation with employment, ${ }^{19}$ while capital intensity and the Herfindahl index are not significant. The results on corporate governance structure and on imports are mixed. The group dummy is positively significant, which could reflect that firms associated with groups are less financially constrained than stand-alone companies. The dummy indicating foreign parent companies is insignificant. The imports are positively significant, which tells us that firms in industries characterized by high import penetration undertake on average more R\&D efforts. Furthermore, there are differences in R\&D investment across industries. The industry dummies are always jointly different from zero in the regressions, and our results emphasize a high correlation of $R \& D$ spending with firms of the Information \& Communication Technology industry. The region dummies also suggest unobserved heterogeneity across states, but these results become insignificant in the heteroscedastic regressions below. The control for market size is always insignificant. 
TABLE 2

Homoscedastic Tobit MOdELS ON R\&D INTENSITY

\begin{tabular}{|c|c|c|c|}
\hline Variables & Model I & Model II & Model III \\
\hline$E M P_{i, t-1} / 1000$ & $\begin{array}{l}0.831 \text { *** } \\
(0.273)\end{array}$ & $\begin{array}{l}0.878 * * * \\
(0.273)\end{array}$ & $\begin{array}{c}0.252 \\
(0.273)\end{array}$ \\
\hline$\left(E M P_{i, t-1} / 1000\right)^{2}$ & $\begin{array}{c}-0.021^{* *} \\
(0.010)\end{array}$ & $\begin{array}{c}-0.022 * * \\
(0.010)\end{array}$ & $\begin{array}{c}-0.004 \\
(0.010)\end{array}$ \\
\hline$K_{A P I N T} T_{i, t-1}$ & $\begin{array}{c}3.265 \\
(2.084)\end{array}$ & $\begin{array}{c}3.187 \\
(2.082)\end{array}$ & $\begin{array}{c}2.818 \\
(2.009)\end{array}$ \\
\hline$H H I_{i, t-1}$ & $\begin{array}{c}-0.001 \\
(0.004)\end{array}$ & $\begin{array}{c}-0.001 \\
(0.004)\end{array}$ & $\begin{array}{c}-0.001 \\
(0.004)\end{array}$ \\
\hline PSTOCK $_{i, t-1}$ & & & $\begin{array}{l}0.037 * * * \\
(0.006)\end{array}$ \\
\hline IPPROTECTION $_{i t}$ & & & $\begin{array}{l}4.017 * * * \\
(0.455)\end{array}$ \\
\hline$L E A D E R_{i t}$ & $\begin{array}{c}-0.101 \\
(0.680)\end{array}$ & $\begin{array}{c}-0.154 \\
(0.679)\end{array}$ & $\begin{array}{c}-0.142 \\
(0.656)\end{array}$ \\
\hline$E N T R Y_{i t}$ & $\begin{array}{l}-0.615^{* * * *} \\
(0.222)\end{array}$ & $\begin{array}{c}-0.891 * * * \\
(0.246)\end{array}$ & $\begin{array}{c}-0.777 * * * \\
(0.238)\end{array}$ \\
\hline$E N T R Y_{i t} \times L E A D E R_{i t}$ & & $\begin{array}{l}0.576^{* * *} \\
(0.217)\end{array}$ & $\begin{array}{l}0.442^{* *} \\
(0.210)\end{array}$ \\
\hline$G R O U P_{i t}$ & $\begin{array}{l}0.946 * * \\
(0.406)\end{array}$ & $\begin{array}{l}0.942 * * \\
(0.406)\end{array}$ & $\begin{array}{c}0.521 \\
(0.392)\end{array}$ \\
\hline FOREIGN $N_{i t}$ & $\begin{array}{c}0.302 \\
(0.590)\end{array}$ & $\begin{array}{c}0.239 \\
(0.589)\end{array}$ & $\begin{array}{c}-0.344 \\
(0.571)\end{array}$ \\
\hline$I M P O R T_{i, t-1}$ & $\begin{array}{l}10.354 * \\
(5.313)\end{array}$ & $\begin{array}{l}10.593 * * \\
(5.307)\end{array}$ & $\begin{array}{c}9.206^{*} \\
(5.117)\end{array}$ \\
\hline MARKETSIZE $E_{i, t-1}$ & $\begin{array}{c}-0.281 \\
(0.245)\end{array}$ & $\begin{array}{c}-0.277 \\
(0.245)\end{array}$ & $\begin{array}{c}-0.303 \\
(0.236)\end{array}$ \\
\hline Intercept & $\begin{array}{c}-5.265^{*} \\
(3.128)\end{array}$ & $\begin{array}{c}-5.443^{*} \\
(3.127)\end{array}$ & $\begin{array}{c}-4.647 \\
(3.018)\end{array}$ \\
\hline Industry dummies $\chi^{2}(13)$ & $250.39^{* * *}$ & $246.58 * * *$ & $162.08 * * *$ \\
\hline Region dummies $\chi^{2}(11)$ & $23.66^{* *}$ & $24.40 * *$ & $27.20 * * *$ \\
\hline Log-likelihood & -3749.23 & -3745.70 & -3676.50 \\
\hline
\end{tabular}

Notes

1857 observations. Standard errors in parentheses.

$* * *, * *, *$ indicate significance levels of $1 \%, 5 \%, 10 \%$, respectively.

As Table 3 shows, the assumption of homoscedasticity is rejected for all models (see Wald tests on heteroscedasticity). The industry and firm size dummies are always jointly significant in the variance equation. However, our main results are robust to the model modification. Leaders, in general, are still not investing in R\&D differently to the outsiders, and R\&D investment is negatively affected by the entry variable. Leaders that suffer from entry threat also invest more than outsiders in the heteroscedastic version. There are no dramatic changes in the estimates of the other covariates. The patent stock is still highly positively significant, and the estimated employment effect remains stable.

To sum up, our findings on entry are in line with our Hypothesis 1, that is, investment decreases with the strength of entry threats. Furthermore, we find that incumbent leaders do not differ in their investment from other firms ( $L E A D E R$ is insignificant), unless they are threatened by endogenous entry. Then the negative investment effect is offset (see the 
TABLE 3

Heteroscedastic Tobit Models ON R\&D INTENSITY

\begin{tabular}{|c|c|c|c|}
\hline Variables & Model I & Model II & Model III \\
\hline$E M P_{i, t-1} / 1000$ & $\begin{array}{l}0.536 * * * \\
(0.104)\end{array}$ & $\begin{array}{l}0.560 * * * \\
(0.104)\end{array}$ & $\begin{array}{l}0.333^{* * *} \\
(0.108)\end{array}$ \\
\hline$\left(E M P_{i, t-1} / 1000\right)^{2}$ & $\begin{array}{c}-0.014 * * * \\
(0.003)\end{array}$ & $\begin{array}{c}-0.015^{* * *} \\
(0.003)\end{array}$ & $\begin{array}{c}-0.008^{* *} \\
(0.003)\end{array}$ \\
\hline$K A P I N T_{i, t-1}$ & $\begin{array}{c}0.526 \\
(0.920)\end{array}$ & $\begin{array}{c}0.516 \\
(0.926)\end{array}$ & $\begin{array}{c}1.119 \\
(0.934)\end{array}$ \\
\hline$H H I_{i, t-1}$ & $\begin{array}{c}-0.001 \\
(0.002)\end{array}$ & $\begin{array}{c}-0.001 \\
(0.003)\end{array}$ & $\begin{array}{c}-0.001 \\
(0.003)\end{array}$ \\
\hline$P_{\text {PSOCK }}$ & & & $\begin{array}{l}0.019 * * * \\
(0.005)\end{array}$ \\
\hline IPPROTECTION $_{i t}$ & & & $\begin{array}{l}2.080 \text { *** } \\
(0.253)\end{array}$ \\
\hline$L E A D E R_{i t}$ & $\begin{array}{c}0.125 \\
(0.266)\end{array}$ & $\begin{array}{c}0.118 \\
(0.264)\end{array}$ & $\begin{array}{c}-0.054 \\
(0.271)\end{array}$ \\
\hline$E N T R Y_{i t}$ & $\begin{array}{c}-0.196 \\
(0.120)\end{array}$ & $\begin{array}{c}-0.321^{* *} \\
(0.132)\end{array}$ & $\begin{array}{c}-0.273^{* *} \\
(0.131)\end{array}$ \\
\hline$E_{N T R} Y_{i t}{ }^{*} L E A D E R_{i t}$ & & $\begin{array}{l}0.308^{* * * *} \\
(0.119)\end{array}$ & $\begin{array}{c}0.270^{* *} \\
(0.120)\end{array}$ \\
\hline$G R O U P_{i t}$ & $\begin{array}{l}0.919 \text { *** } \\
(0.243)\end{array}$ & $\begin{array}{l}0.936^{* * *} \\
(0.243)\end{array}$ & $\begin{array}{l}0.705^{* * * *} \\
(0.246)\end{array}$ \\
\hline FOREIGN $N_{i t}$ & $\begin{array}{l}0.537^{* *} \\
(0.271)\end{array}$ & $\begin{array}{c}0.494 * \\
(0.270)\end{array}$ & $\begin{array}{c}0.103 \\
(0.262)\end{array}$ \\
\hline$I M P O R T_{i, t-1}$ & $\begin{array}{l}8.160 * * \\
(4.001)\end{array}$ & $\begin{array}{l}8.262^{* *} \\
(3.969)\end{array}$ & $\begin{array}{l}8.152^{* *} \\
(3.858)\end{array}$ \\
\hline MARKETSIZE $E_{i, t-1}$ & $\begin{array}{r}-0.233^{*} \\
(0.133)\end{array}$ & $\begin{array}{c}-0.223 \\
(0.133)\end{array}$ & $\begin{array}{c}-0.169 \\
(0.135)\end{array}$ \\
\hline Intercept & $\begin{array}{c}-0.912 \\
(1.607)\end{array}$ & $\begin{array}{c}-1.173 \\
(1.610)\end{array}$ & $\begin{array}{c}-1.872 \\
(1.656)\end{array}$ \\
\hline Industry dummies $\chi^{2}(12)$ & $127.10^{* * *}$ & $127.85 * * *$ & $86.68 * * *$ \\
\hline Region dummies $\chi^{2}(11)$ & 13.03 & 12.99 & 11.81 \\
\hline Log-likelihood & -3509.37 & -3505.95 & -3451.55 \\
\hline Wald test on heteroscedasticity $\chi^{2}(17)$ & $535.45^{* * * *}$ & $531.96 * * *$ & $496.55^{* * *}$ \\
\hline
\end{tabular}

Notes

1857 observations. Standard errors in parentheses.

$* * *, * *, *$ indicate significance levels of $1 \%, 5 \%, 10 \%$, respectively.

positive sign of the interaction term $\left.L E A D E R_{i} \times E N T R Y_{i}\right)$. Thus incumbents invest more than the outsiders under endogenous entry threat. In line with our Hypothesis 2 , the competitive pressure of the potential entry of other firms induces the market leaders to invest in R\&D more than any other firm.

In economic terms, the findings are also highly significant. Calculating the expected value of $R D I N T_{i}$ for outsiders under no entry threat yields ${ }^{20}$

$$
E\left(\operatorname{RDINT}_{i} \mid \operatorname{LEADER}_{i}=0, \operatorname{ENTR}_{i}=0, \bar{X}_{i}\right)=0.81,
$$

where the covariates are taken at the average $\bar{X}_{i}{ }^{21}$ In contrast, the investment intensity of outsiders under high entry threat only amounts to 


$$
E\left(\operatorname{RDINT}_{i} \mid \operatorname{LEADER}_{i}=0, \operatorname{ENTR}_{i}=3, \bar{X}_{i}\right)=0.42,
$$

which means that R\&D intensity reduces by about $52 \%$, all else constant. If a leader suffers from high entry threat, however, we obtain

$$
E\left(R D I N T_{i} \mid L E A D E R_{i}=1, \operatorname{ENTR}_{i}=3, \bar{X}_{i}\right)=0.78
$$

which corresponds to an about $90 \%$ higher investment for the leaders of markets with endogenous entry compared to their followers. ${ }^{22}$

\section{Results on reverse causality between $R \& D$ and entry}

In this subsection we verify whether there is a problem of reverse causality for which high R\&D intensity of a generic firm induces low entry threat, and vice versa.

First, we test if the above mentioned instrumental variables are relevant in the firststage regression of entry on all covariates and the excluded instruments. Table 4 shows the partial $F$-values for the instrumental variables in the first-stage regression.

Then we test for reverse causality in the second-stage regression following Smith and Blundell (1986). They introduced a regression-based test that is basically equivalent to the procedure suggested by Hausman $(1978,1983)$ for the OLS case. ${ }^{23}$ Suppose that our $\mathrm{R} \& \mathrm{D}$ investment equation is given by

$$
y_{i 1}^{*}=x_{i}^{\prime} \beta+\alpha y_{i 2}+u_{i},
$$

where the possibly endogenous regressor $y_{2}$ is the entry threat in our case, and the vector $x_{i}$ denotes the other regressors. Then we write the reduced form equation for $y_{2}$ as

$$
y_{i 2}=z_{i}^{\prime} \pi+v_{i},
$$

where $z_{i}^{\prime}$ contains the vector $x$ and the other instrumental variables described above. Once we estimate (7) and obtain $\hat{v}_{i}$, we can estimate our R\&D equation including the generated residuals from the first-stage regression using Tobit as

$$
y_{i 1}^{*}=x_{i}^{\prime} \beta+\alpha y_{i 2}+\rho \hat{v}_{i}+e_{i} .
$$

TABle 4

IV RELEVANCE TESTS AND ENDOGENEITY TEST OF ENTRY VARIABle

\begin{tabular}{llcc}
\hline Test & $M_{t-1}$ & MES $_{t-1}, N E W K A P_{t}$ & NEWKAP $_{t}, \Delta M A T \%_{t} \%_{t}$ \\
\hline$F$-test on IV significance in & $F=10.84^{* * *}$ & $F=9.79^{* * *}$ & $F=8.68^{* * *}$ \\
$\quad$ first-stage regression & & & -1.509 \\
Blundell-Smith endogeneity test ${ }^{\mathrm{a}}$ & -0.496 & -0.882 & 3.494 \\
Exogeneity test $^{\mathrm{b}}$ & - & 0.002 & \\
\hline
\end{tabular}

Notes

$* * *, * *, *$ indicate significance levels of $1 \%, 5 \%, 10 \%$, respectively.

${ }^{a}$ Based on heteroscedastic Model I. $t$-statistics of first-stage residuals are displayed.

${ }^{\mathrm{b}}$ Amemiya-Lee-Newey minimum $\chi^{2}$ statistic (see Newey 1987; Lee 1992; Baum et al. 1999). 
The usual $t$-statistic of $\hat{\rho}$ is a valid test on the endogeneity of $y_{2}$. If it is not rejected that $\hat{\rho}=0$, we do not find that $y_{i 2}$ is explained $y_{i 1}^{*}$.

Table 4 reports the IV relevance tests from the first-stage regression (partial $F$-statistics), and the Smith-Blundell test on endogeneity of ENTRY (where endogeneity here is in the econometric sense) based on the heteroscedastic regressions of Model I (the homoscedastic version led to the same conclusions).

Staiger and Stock (1997) emphasized that the first-stage significance levels of the instrumental variables may be misleading, as they do not necessarily exclude a weak instrument problem, which would lead to considerable bias in IV regressions. Instead of interpreting the significance level, they argue - as rule of thumb - that the partial $F$-statistic should be around 10 in the case of a single endogenous regressor, to confidently rule out weak instruments. As can be seen in Table 4, all $F$-values are around 10, and consequently we should not be concerned about a weak instrument bias.

Furthermore, we test whether the instrumental variables are uncorrelated with the error term in our structural equation. Only if we are confident of having no weak instrument problem, and the instruments are not correlated with the error term in the R\&D equation, we can rely on our IV results. As we estimate Tobit models, we use the AmemiyaLee-Newey minimum $\chi^{2}$ statistic to test for the exogeneity of our instruments. ${ }^{24}$

As a final step, we test for endogeneity of ENTRY using the Smith-Blundell test. As the results in Table 4 show, the exogeneity of ENTRY with respect to R\&D investment is not rejected. The corresponding regression results for the first stage of the IV procedure are shown in Table A2 in the Appendix.

In summary, we found relevant instrumental variables, but the potential reverse causality has been rejected by the tests. Given these results, we conclude that the results as presented in Table 3 still hold, and that our two main hypothesis are thus confirmed: R\&D investment decreases with larger entry threats in general, but leaders invest more into R\&D when threatened by entry.

In addition to the feedback effect from $R \& D$ to entry, some readers may be concerned about the feedback from R\&D to our variable $L E A D E R$. We simply checked if past R\&D intensity (which we have for a subsample of about 1000 companies) determines our leadership variable to a certain extent. For this, we simply regressed $L E A D E R$ on past R\&D intensity, past sales and industry dummies. It turns out that past sales, and thus past firm size, dominate the relationship. There is no additional effect of past $R \& D$ beyond firm size.

\section{CONCLUSIONS}

Who does invest in R\&D? This paper has provided theoretical and empirical motivations for a relatively surprising answer to this question: market leaders do invest in R\&D more than other firms when they are under the competitive pressure of endogenous entrants, while they appear to invest as the other firms in markets with barriers to entry. The immediate consequence is that under endogenous entry, incumbents are more likely to innovate and therefore to persist in their leading position, while incumbents that do not face entry pressure tend to be less innovative (and therefore tend to be replaced). This result suggests that we may have to change our way of looking at persistent dominance in a technologically advanced market: this may be the result of strong competitive pressures.

A novel aspect of our empirical approach is given by the fact that the same firms provide a subjective view on our key determinants of R\&D intensity, the entry pressure and the leadership. Rather than determining arbitrarily the size and composition of a market, 
assigning a degree of entry intensity in a discretionary way and assigning a status of leadership on the basis of predetermined variables, using the questionnaire of the Mannheim Innovation Panel, we allow the firms to identify the size of their main market, the existence of an endogenous threat of entry in the market and the identity of the leader in the market.

Our empirical approach can be seen as a first attempt to test the predictions of the endogenous market structures approach and could be applied to other empirical implications, for instance, on on the role of leaders in pricing strategies, preliminary investment decisions (capacity building or advertising), contractual strategies (such as vertical contracts, bundling decisions, incentives contracts for managers and workers), financial decisions, and so on.

\section{APPENDIX}

TABLE A1

SAMPLE DESCRIPTION BY INDUSTRY AGGREGATES

\begin{tabular}{lccc}
\hline Industry & $\begin{array}{c}\text { No. of } \\
\text { observations }\end{array}$ & $\begin{array}{c}\text { No. of } \\
\text { leaders }\end{array}$ & $\begin{array}{c}\text { Average R\&D } \\
\text { intensity (\%) }\end{array}$ \\
\hline Food & 121 & 13 & 0.33 \\
Textiles/Leather & 97 & 9 & 1.21 \\
Paper/Wood & 189 & 11 & 0.85 \\
Publishing/Printing & 117 & 12 & 0.54 \\
Chemicals & 132 & 6 & 3.50 \\
Rubber & 138 & 9 & 1.16 \\
Glass/Ceramics & 82 & 11 & 0.93 \\
Metal production & 61 & 5 & 0.63 \\
Metal fabrication & 259 & 23 & 1.09 \\
Machinery & 222 & 7 & 2.68 \\
Electronics & 109 & 3 & 2.51 \\
ICT & 70 & 14 & 5.65 \\
Instruments/Optics & 172 & 4 & 7.10 \\
Vehicles & 88 & 149 & 2.37 \\
Total & 1857 & & \\
\hline
\end{tabular}

TABLE A2

IV FIRST-STAGE REGRESSIONS ON ENTRY

\begin{tabular}{lccc}
\hline Variables & Model I & Model II & Model III \\
\hline$E M P_{i, t-1} / 1000$ & -0.049 & -0.046 & -0.047 \\
$\left(E M P_{i, t-1} / 1000\right)^{2}$ & $(0.035)$ & $(0.034)$ & $(0.034)$ \\
& 0.001 & 0.001 & 0.001 \\
$K A P I N T_{i, t-1}$ & $(0.0009)$ & $(0.0009)$ & $(0.0009)$ \\
& 0.106 & 0.152 & 0.150 \\
$H H I_{i, t-1}$ & $(0.243)$ & $(0.242)$ & $(0.241)$ \\
& -0.00003 & -0.00006 & -0.00005 \\
& $(0.0004)$ & $(0.0004)$ & $(0.0004)$ \\
\hline
\end{tabular}


TABLE A2

CONTINUED

\begin{tabular}{|c|c|c|c|}
\hline Variables & Model I & Model II & Model III \\
\hline$L E A D E R_{i t}$ & $\begin{array}{c}-0.229 * * * \\
(0.069)\end{array}$ & $\begin{array}{c}-0.239 * * * \\
(0.069)\end{array}$ & $\begin{array}{c}-0.235^{* * *} \\
(0.068)\end{array}$ \\
\hline$G R O U P_{i t}$ & $\begin{array}{c}0.034 \\
(0.043)\end{array}$ & $\begin{array}{c}0.031 \\
(0.043)\end{array}$ & $\begin{array}{l}0.027^{* * *} \\
(0.043)\end{array}$ \\
\hline FOREIGN $N_{i t}$ & $\begin{array}{c}-0.122 * \\
(0.067)\end{array}$ & $\begin{array}{c}-0.115 \\
(0.067)\end{array}$ & $\begin{array}{c}-0.113 \\
(0.067)\end{array}$ \\
\hline$I M P O R T_{i, t-1}$ & $\begin{array}{r}-0.519 \\
(0.560)\end{array}$ & $\begin{array}{r}-0.978^{*} \\
(0.579)\end{array}$ & $\begin{array}{r}-0.755 \\
(0.585)\end{array}$ \\
\hline MARKETSIZE $E_{i, t-1}$ & $\begin{array}{c}-0.005 \\
(0.026)\end{array}$ & $\begin{array}{c}0.001 \\
(0.025)\end{array}$ & $\begin{array}{c}0.010 \\
(0.026)\end{array}$ \\
\hline$P S T O C K_{i, t-1}$ & $\begin{array}{c}-0.002 * * \\
(0.001)\end{array}$ & $\begin{array}{c}-0.002 * * \\
(0.001)\end{array}$ & $\begin{array}{c}-0.002^{* *} \\
(0.001)\end{array}$ \\
\hline IPPROTECTION $_{i t}$ & $\begin{array}{c}0.010 \\
(0.053)\end{array}$ & $\begin{array}{c}0.018 \\
(0.053)\end{array}$ & $\begin{array}{c}0.016 \\
(0.053)\end{array}$ \\
\hline$M E S_{i, t-1}$ & $\begin{array}{l}-0.327^{* * *} \\
(0.099)\end{array}$ & $\begin{array}{c}-0.311^{* * *} \\
(0.100)\end{array}$ & $\begin{array}{c}-0.325^{* * *} \\
(0.100)\end{array}$ \\
\hline$N E W K A P_{i t}$ & & $\begin{array}{l}-5.144 * * * \\
(1.667)\end{array}$ & $\begin{array}{c}-4.581^{* * *} \\
(1.698)\end{array}$ \\
\hline$\triangle M A T \%_{i t}$ & & & $\begin{array}{c}-0.219^{* *} \\
(0.089)\end{array}$ \\
\hline Intercept & $\begin{array}{l}1.699 * * * \\
(0.309)\end{array}$ & $\begin{array}{l}1.790^{* * * *} \\
(0.315)\end{array}$ & $\begin{array}{l}1.666^{* * *} \\
(0.317)\end{array}$ \\
\hline$F$-test industry dummies & $2.53 * * *$ & $2.84 * * *$ & $3.04 * * *$ \\
\hline$F$-test region dummies & 0.59 & 0.57 & $0.58 * *$ \\
\hline$F$-test IVs & $10.84 * * *$ & $9.79 * * *$ & $8.68 * * *$ \\
\hline
\end{tabular}

Notes

1857 observations. Standard errors in parentheses.

$* * *, * *, *$ indicate significance levels of $1 \%, 5 \%, 10 \%$, respectively.

' $F$-test IVs' refers to a joint significance test of our instrumental variables, which are $M E S$ in Model I, $M E S$ and NEWKAP in Model II, and MES, NEWKAP and $\triangle M A T \%$ in Model III.

\section{ACKNOWLEDGMENTS}

We are grateful to participants at the Intertic Conference on Endogenous Market Structures and Industrial Policy, at the ZEW Conference on the Economics of Innovation and Patenting, at the CRESSE Conference in Athens, and at seminars at TILEC (Tilburg University) and the University of Milan, Bicocca, including Cédric Argenton, Jan Boone, Filomena Chirico, Christian Köhler, Jaanika Merikull, Frederic Scherer, Wieland Müller and especially Richard Schmalensee, Frode Steen and Andrew Toole.

\section{NOTES}

1. Moreover, taking this view literally, we should conclude that whenever we observe monopoly persistence, it is because the incumbent firm is more efficient than the other firms at both producing and innovating. There are many sectors in which incumbents do not appear to have any cost advantage in the development of innovations compared to outsiders, and still both the incumbents and the entrants keep investing.

2. See Sutton $(1998,2007)$ and Etro $(2007)$ for reviews of this literature.

3. Aghion and Howitt (2009, ch. 14) have forcefully advanced an 'escape competition' rationale for investment by incumbents under entry, but their models rely on the assumption that a single incumbent faces an 
exogenous probability of entry (or an endogenous probability that a single rival may replace its leadership). Under endogenous entry of outsiders, their incumbent would not invest as usual as a consequence of the Arrow effect (and the escape competition effect would disappear as well).

4. As noticed by a referee, the empirical results provide evidence for a more general class of theories, namely those based on endogenous market structures, in which market leaders behave differently from the other firms, always in an aggressive way. Here we focus on R\&D, but one can see this as a first attempt to test the recent models of endogenous market structures.

5. Aghion et al. (2009) provide additional empirical evidence on the impact of entry on incumbents' investments. For an alternative empirical investigation of the same result, see Adams and Clemmons (2008).

6. One can think of the strength of intellectual property rights protection and of the importance of patents as the determinants of the expected prize $V$. The assumption of a drastic innovation is not crucial for our results, as in the model of Gilbert and Newbery (1982), which considers a contest with certainty (basically an auction for a patent) and ignores risk in the R\&D investment. See Etro (2004, Sec. 2.2) on the case of non-drastic innovations in patent races with uncertainty.

7. The assumption of quadratic costs could be replaced with any convex cost function without altering the nature of the following results. Its role is only to provide closed forms solutions at least for the equilibria with endogenous market structure.

8. Indeed, $\Pi_{i}=d z^{2} / 2-F$, where $z$ is decreasing in $n$, and $z \rightarrow 0$ for $n \rightarrow \infty$. Notice also that the probability that someone innovates is $\operatorname{Pr}(\operatorname{Inn})=1-(1-z)^{n}=1-z(1-z) d / V$.

9. When the fixed costs tend to zero, each firm tends to invest an infinitesimal amount, but the number of firms grows unboundedly; this reproduces a perfectly competitive outcome where the innovation is obtained for sure, since $\operatorname{Pr}(\operatorname{Inn})=1-(1-z)^{n} \rightarrow 1$.

10. Measuring welfare as $\operatorname{Pr}(\operatorname{Inn}) V-n d z^{2} / 2-n F$, the optimal investment rule is the same as in (1), but the first-order condition for the optimal number of firms is

$$
\log \left(\frac{1}{1-z}\right)(1-z)^{n} V=\frac{d z^{2}}{2}+F,
$$

which requires always a lower number of firms than in equilibrium-indeed, $\log (1-z)^{-1}<z /(1-z)$ for any $z \in(0,1)$. Of course, if the social value of innovation is higher than the private value, then we may have too few firms in equilibrium.

11. Of course, in case of a high fixed cost of entry, the incumbent may also find it optimal to deter entry.

12. Gilbert and Newbery (1982, p. 521) briefly analyse the case of uncertain contests, suggesting that entry deterrence could also occur in that case: 'The monopolist can guarantee negative expected profits to any potential entrant, and knowing this, firms would not invest in R\&D ... the monopolist has to set up the correct number of rival research teams - the same number of firms who would choose to enter under competitive conditions'.

13. See De Bondt and Vandekerckhove (2008) for further extensions of this result to the case of R\&D spillovers between firms.

14. This stream of literature has been extended by Reinganum (1985) among many others.

15. Of course, whenever there is no firm in a market that perceives itself as larger than its competitors, the market has no leader and competition is supposed to be symmetric.

16. Note that the HHI ranges between 0 and 1000 in the official statistics, and not between 0 and 10,000 as is commonly used in the USA.

17. Lyons et al. (2001) use engineering estimates based on the firms' technologies employed in the production process.

18. NACE is the European standard industry classification, and the firms in our sample are active in 96 different NACE three-digit industries.

19. The inverted U curve peaks at about 20 thousand employees. As we have only a single observation that has more employees, we can basically conclude that R\&D investment is increasing and concave in firm size.

20. See Greene (2003, pp. 768-9) for the computation of the expected value in Tobit models.

21. Calculations are based on the heteroscedastic estimation of Model III.

22. Notice also that compared to the expected value of a firm in a market without entry threat, the investment reduction by a leader due to entry is not significantly different from zero.

23. See also Wooldridge (2002, pp. 118-20).

24. See Amemiya (1978), Newey (1987), Lee (1992) and Baum et al. (1999).

\section{REFERENCES}

Acemoglu, D. (2009). Introduction to Modern Economic Growth. Princeton, NJ: Princeton University Press. and CAO, D. V. (2010). Innovation by entrants and incumbents. NBER Working Paper no. 16411. and LINN, J. (2004). Market size and innovation: theory and evidence from the pharmaceutical industry. Quarterly Journal of Economics, 119, 1049-90. 
Adams, J. and Clemmons, J. R. (2008). Invention and discovery in science-based firms. Mimeo, University of Florida.

Aghion, P. and Howitt, P. (1992). A model of growth through creative destruction. Econometrica, 60(2), 32351. - and - (2009). The Economics of Growth. Cambridge, MA: MIT Press.

, Blundell, R., Griffith, R., Howitt, P. and Prantl, S. (2009). The effects of entry on incumbent innovation and productivity. Review of Economics and Statistics, 91(1), 20-32.

Amemiya, T. (1978). The estimation of a simultaneous equation generalized probit model. Econometrica, 46(5), 1193-205.

Arrow, K. (1962). Economic welfare and the allocation of resources for invention. In R. R. Nelson (ed.), The Rate and Direction of Innovative Activity. Princeton, NJ: Princeton University Press.

Baum, C. F., Wiggins, V., Stillman, S. and Schaffer, M. E. (1999). OVERID: Stata module to calculate tests of overidentifying restrictions after ivreg, ivreg2, ivreg29, ivprobit, ivtobit, reg3. Statistical Software Components S396902, Boston College Department of Economics; revised 26 April 2010.

DAsGupta, P. and Stiglitz, J. (1980). Uncertainty, industrial structure and the speed of R\&D. Bell Journal of Economics, 11, 1-28.

De Bondt, R. and VAndeKerckhove, J. (2008). Innovation races with reward sharing. Review of Business and Economics, 53, 354-74.

Etro, F. (2004). Innovation by leaders. Economic Journal, 114(495), 281-303.

(2006). Aggressive leaders. RAND Journal of Economics, 37, 146-54.

(2007). Competition, Innovation, and Antitrust. Berlin: Springer.

(2008). Stackelberg competition with endogenous entry. Economic Journal, 118(532), 1-28.

Eurostat (2004). Innovation in Europe results for the EU, Iceland and Norway. Panorama of the European Union: Edition 2004. Luxembourg: Eurostat.

Eurostat (2008). Science, Technology and Innovation in Europe. Luxembourg: Eurostat.

Gilbert, R. and Newbery, D. (1982). Preemptive patenting and the persistence of monopoly. American Economic Review, 72(3), 514-26.

Greene, W. (2003). Econometric Analysis, 5th edn. Upper Saddle River, NJ: Prentice Hall.

Griliches, Z. and Mairesse, J. (1984). Productivity and R\&D at the firm level. In Z. Griliches (ed.), $R \& D$, Patents and Productivity. Chicago, IL: University of Chicago Press, pp. 152-75.

Gschwandtner, A. and Lambson, V. E. (2012). Sunk costs, depreciation and industry dynamics. Review of Economics and Statistics, 94(4), 1059-65.

Hausman, J. (1978). Specification tests in econometrics. Econometrica, 46(6), 1273-91.

(1983). Specification and estimation of simultaneous equations models. In Z. Griliches and M. D. Intriligator (eds), Handbook of Econometrics, Vol. 1. Amsterdam: North-Holland.

KovÁČ, E., Vinogradov, V. and ŽIgIĆ, K. (2010). Technological leadership and the persistence of monopoly under endogenous entry: static versus dynamic analysis. Journal of Economic Dynamics and Control, 34(8), $1421-41$.

LEE, L. F. (1992). Amemiya's generalized least squares and tests of overidentification in simultaneous equation models with qualitative or limited dependent variables. Econometric Reviews, 11(3), 319-28.

Lyons, B., Matraves, C. and Moffatt, P. (2001). Industrial concentration and market integration in the European Union. Economica, 68, 1-26.

MACI, I. and ŽIGIĆ, K. (2011). Competition policy and market leaders. Economic Modelling, 28(3), 1042-9.

NEWEY, W. K. (1987). Efficient estimation of limited dependent variable models with endogeneous explanatory variables. Journal of Econometrics, 36, 231-50.

OECD and Eurostat (1997). Oslo Manual_Proposed Guidelines for Collecting and Interpreting Technological Innovation Data. Paris: OECD.

ReINGANUM, J. F. (1985). Innovation and industry evolution. Quarterly Journal of Economics, 100, 81-99.

Segerstrom, P. (2007). Intel economics. International Economic Review, 48(1), 247-80.

Smith, R. and Blundell, R. (1986). An exogeneity test for a simultaneous equation Tobit model with an application to labor supply. Econometrica, 54(3), 679-85.

StAiger, D. and Stock, J. H. (1997). Instrumental variables regression with weak instruments. Econometrica, 65(3), 557-86.

SutTon, J. (1998). Technology and Market Structure. Cambridge, MA: MIT Press.

- (2007). Market structure: theory and evidence. In M. Armstrong and R. Porter (eds), Handbook of Industrial Organization, Vol. 3. Amsterdam: North-Holland, pp. 2301-68.

Wooldridge, J. (2002). Econometric Analysis of Cross Section and Panel Data. Cambridge, MA: MIT Press. 